\title{
CRITINFÂNCIA: Novas trilhas e sentidos para a educação da infância em tempos de resistência
}

\author{
CRITIQUE-CHILDHOOD: New trails and directions for childhood education in times of resistance \\ Marta Regina Furlan de Oliveira ${ }^{1}$ \\ Alex Sander da Silva ${ }^{2}$
}

http://dx.doi.org/10.52641/cadcaj.v6i4.532

\begin{abstract}
RESUMO: Este texto objetiva refletir sobre a infância, educação e teoria crítica em tempos de resistência, bem como o processo formativo docente em prol do sentido de educar a criança em torno da formação humana e emancipatória do ensino. Justifica-se por consideração ao trabalho desenvolvido em 2020 em meio à pandemia, com a organização do IV Simpósio Nacional e I Simpósio Internacional sobre a Infância, Educação e Teoria Crítica e, que partiu dos respectivos Grupos de Estudo e Pesquisa em Educação: GEPEITC - Grupo de Estudos e Pesquisa em Educação, Infância e Teoria Crítica da Universidade Estadual de Londrina (UEL) e do GEFOCS - Grupo de Estudos e Pesquisa em Educação, Formação Cultural e Sociedade da Universidade do Extremo Sul Catarinense (UNESC). A metodologia envolve os fundamentos de Teoria Crítica de Sociedade e outros diálogos críticos em torno da temática central do evento. Ainda, apresenta o trabalho formativo desenvolvido entre 06 e 09 de outubro do ano de 2020 envolvendo palestras, conferências, relatos de experiência, relatos de projetos de pesquisa dos respectivos grupos já nominados. As atividades desenvolvidas contaram com a participação de professores de várias instituições brasileiras e, ainda, de Portugal, Chile e Peru. Os resultados direcionaram para o olhar de (re) invenção e busca de novos sentidos ao processo formativo docente com vistas a desbarbarização do trabalho na educação da infância por meio da resistência e crítica imanente.
\end{abstract}

Palavras-chave: Educação. Formação de Professores. Critinfância. Teoria Crítica.

Abstract: This text aims to reflect on childhood, education and critical theory in times of resistance, as well as the teacher training process in favor of the sense of educating the child about human and emancipatory education. It is justified in consideration of the work developed in 2020 in the midst of the pandemic, with the organization of the IV National Symposium and I International Symposium on Childhood, Education and Critical Theory and, which started from the respective Study and Research Groups in Education: GEPEITC - Study and Research Group on Education, Childhood and Critical Theory at the State University of Londrina (UEL) and GEFOCS - Study and Research Group on Education, Cultural Formation and Society at the University of the Extreme South of Santa Catarina (UNESC). The methodology involves the foundations of Critical Theory of Society and other critical dialogues around the central theme of the event. Still, it presents the training work developed between 06 and 09 October of the year

\footnotetext{
${ }_{1}^{1}$ Pós doutora em Educação pela Universidade Estadual Paulista Júlio de Mesquita Filho. Doutora em Educação pela Universidade Estadual de Maringá (UEM). Docente do Departamento de Educação e do Programa de PósGraduação em Educação da Universidade Estadual de Londrina (UEL). Lattes: http://lattes.cnpq.br/8423465824507075. ORCID: $\quad \underline{\text { http://orcid.org/0000-0003-2146-2557. }}$ E-mail: marta.furlan@yahoo.com.br

${ }^{2}$ Pós doutor em Educação pela Universidade Metodista de Piracicaba. Doutor em Educação pela Pontifícia Universidade Católica do Rio Grande do Sul. Docente do Programa de Pós-Graduação em Educação da Universidade do Extremo Sul Catarinense. Lattes: http://lattes.cnpq.br/2850514083704546 ORCID: https://orcid.org/0000-0002-0945-9075 E-mail: alexsanders@unesc.net
} 
2020 involving lectures, conferences, reports of experience, reports of research projects of the respective groups already nominated. The activities carried out counted on the participation of professors from several Brazilian institutions and, also, from Portugal, Chile and Peru. The results led to the look of (re) invention and the search for new meanings for the teaching formative process with a view to disarming work in childhood education through resistance and immanent criticism.

Keywords: Education. Teacher training. Critinfance. Critical Theory.

\title{
1. INTRODUÇÃO
}

\begin{abstract}
O menino pergunta ao eco. Onde é que ele se esconde. Mas o eco só responde: Onde? Onde? O menino também lhe pede: Eco, vem passear comigo! Mas não sabe se o eco é amigo ou inimigo. Pois só the ouve dizer: Migo! (Cecilia Meireles, Eco)

O pensamento aguarda que, um dia, a lembrança do que foi perdido venha despertá-lo e o transforme em ensinamento. (Theodor W. Adorno)
\end{abstract}

As epígrafes de Cecília Meireles "Eco" e de Theodor Adorno nos convida a pensar sobre o século XXI e suas questões problemáticas de ordem social, educacional e formativa. Em relação ao tempo atual, uma questão de saúde pública afetou o cenário mundial em seus mais diversos campos, trazendo consequências econômicas, políticas, sociais e, logo, também, ao campo educacional que se deparou com a pandemia da Covid-19. O mundo e, especificamente, o Brasil, tiveram que "parar" a maneira de vida e relação humana e, adentrar em um novo formato de convivência que, no caso, denominou-se de isolamento ou distanciamento social. O medo e a incerteza associaram-se ao termo imperativo "fica em casa" que, de forma ampla, ressoou por todos os cantos da vida social provocando desafios, enfrentamentos e resistências.

Assim, logo nos primeiros 30 (trinta) dias de contagio mundial e massivo do vírus, constatou-se um cenário marcado por crianças, adolescentes e jovens "fora" da escola. O verbo esperançar assumiu seu valor com o pensamento de um possível retorno ao mundo escolar, o que não aconteceu plenamente até o presente momento no Brasil e, de maneira tímida em outros países, como é o caso de Portugal, por exemplo. Ao contrário, a paralisação provocada pelo “inimigo invisível” (Covid-19) potencializou notáveis interrupções no campo formativo e na educação da infância, sendo esse o nosso objeto de estudo neste texto.

A educação da infância, em específico, que por sua especificidade lúdica trilhava pelas práticas afetivamente interativas e de protagonismo compartilhado entre professores e crianças, agora se vê em um grande paradoxo em busca de novos direcionamentos em meio ao caos, a dor e, as incertezas. Pela mesma trilha se vê o professor que, até o momento do contágio em massa do vírus, se enveredava por intenções de cuidado, educação e brincadeira e, agora clama por um 
lugar que garanta o brincar e a descoberta fascinante do mundo pela criança e de seu protagonismo mediado pela ação docente. Por conseguinte, Sarmento (2016, p.79) considera que:

\begin{abstract}
refletir sobre as identidades profissionais de educadoras de infância obriga a analisar um processo de construção social, na qual cada uma joga a sua história de vida com a história de vida do grupo profissional a que pertence, com as crianças, com as comunidades e com os contextos onde se desenvolve a sua ação educativa, transformando e permitindo-se transformar, nessa teia de interações numa forma própria de ser e de agir.
\end{abstract}

A disparada suicida do vírus se viu reajustada na educação da infância com o uso do recurso tecnológico que, se em outro momento, era visto como preocupante e até adestrador da vida e das relações, nesse contexto pandêmico, especificamente no Brasil, tornou-se a estratégia inovadora da educação e, porque não a possível "solução" para muitos. A centralidade de iniciativas voltou-se ao cumprimento de carga horária associada aos conteúdos, com o uso de plataformas virtuais, redes sociais, correio eletrônico, recursos de videoaulas e outros. Nesta disponibilização de ferramentas online para a realização de atividades não presenciais, os mais conhecidos são: Google Meet, Zoom, Google Hangouts, Skype e ambientes de sala de aula online como o Google Classromm, que se firmaram enquanto meio de diálogo e interação de professores e crianças por meio do ensino remoto e sem distância.

Sarmento (2016) considera que se até o presente momento tem se lutado para que as crianças pequenas se mantivessem afastadas do uso intensivo destes dispositivos, agora é a própria escola que "impõe" que olhem para eles, mais tempo do que era habitual, para que, desta forma, possam continuar a aprender. Por esta via, a infância também é constituída pelos limiares sociais e históricos que, de certa forma, estão em constante mudanças. "Entende-se, assim, a infância como realidade social emergente no âmbito de um conjunto de processos sociais e culturais, entre outros" (SARMENTO, 2016, p.77).

A Pandemia no mundo registrou travessias na educação e no ensino pela forma remota revelando enfaticamente um tempo marcado de incertezas na vida social e formativa de crianças. Essa situação parece negar nossa situação de excepcionalidade, em que se mostram as condições de desigualdade em que vivemos, também no acesso aos recursos tecnológicos. Se no ensino presencial, muitas crianças foram negligenciadas em sua subjetividade, com o ensino à distância, estas acabam ficando "para trás" e "sem voz".

Sobre isso, Benjamin (1985) tece suas críticas à negação da experiência que permeia a modernidade e ao risco que ela traz, o qual reside na ausência do espaço para a experiência e na possibilidade de se perder a capacidade de narrar, de contar a sua própria história. Em relação a infância, aferimos que existe um tempo de experiência vital pela qual passamos, que é compartilhada e experimentada de várias maneiras. A infância pode ser entendida não apenas 
como uma etapa cronológica, como habitualmente conhecemos, mas, também, como uma condição da experiência humana que se coloca como latência, como tensão constante entre tempo e experiência. É o ponto de partida para reflexões sobre a formação do sujeito, seu modo de pensar e agir. Sua dignidade nos parece estar no fato de se ter algo como horizonte de possibilidade para pensar sua própria condição no mundo contemporâneo.

Em Kohan (2007, p. 113), a infância exige pensar numa temporalidade para além do tempo "normal" da existência humana, das etapas da vida e das fases do desenvolvimento que, de certa forma, ocupa um lugar de debilidade. Está mais articulada a uma possibilidade de intensificar certa relação com o tempo, de instaurar um outro tempo e se envolver num círculo repleto de intensidades. De antemão, "o tempo infantil, é o tempo circular, do eterno retorno, sem a sucessão consecutiva do passado, presente e futuro, mas com a afirmação intensiva de um outro tipo de existência” (KOHAN, 2007, p. 114).

Por ser a infância e a educação infantil a nossa causa, intenciona-se que toda criança tem direito a uma escola equitativa, plural e acolhedora, ou seja, um espaço na qual possa contar com a educação e o cuidado apropriados ao seu desenvolvimento e em que seja respeitada a sua condição peculiar de pessoa em formação. Por conseguinte, esta proposta é pertinente por potencializar o pensar crítico sobre a gestação desse tempo sombrio que se propaga de maneira "violenta" e, conduz os indivíduos a viver na ilha cercada por ameaças de todos os lados, inclusive do lado de dentro de nós.

Por conseguinte, este texto objetiva refletir sobre a infância, educação e teoria crítica em tempos de resistência, bem como o processo formativo docente em prol do sentido de educar a criança em torno da formação humana e emancipatória do ensino.

A justificativa se constitui em relação ao trabalho desenvolvido em 2020 com a organização do IV Simpósio Nacional e I Simpósio Internacional sobre a Infância, Educação e Teoria Crítica e, que partiu dos respectivos Grupos de Estudo e Pesquisa em Educação: GEPEITC - Grupo de Estudos e Pesquisa em Educação, Infância e Teoria Crítica da Universidade Estadual de Londrina (UEL) e do GEFOCS - Grupo de Estudos e Pesquisa em Educação, Formação Cultural e Sociedade da Universidade do Extremo Sul Catarinense (UNESC). A intencionalidade do evento se firmou pela preocupação em relação ao processo formativo docente a fim de que para além de uma homogeneização temática, pudéssemos enveredar pelas trilhas de discussões voltadas ao reconhecimento da infância nas muitas infâncias envolvidas em mundo de muitos mundos.

A metodologia se constitui em discussões sobre a infância, educação e formação de professores pelos limiares dos fundamentos da Teoria Crítica de Sociedade e de outros diálogos 
críticos em torno da temática central do evento. Ainda, apresenta o trabalho formativo desenvolvido entre 06 e 09 de outubro do ano de 2020 envolvendo uma organização à partir de palestras, conferências, relatos de experiência, relatos de projetos de pesquisa dos respectivos grupos já nominados. As atividades desenvolvidas contaram com a participação de professores de várias instituições brasileiras e, ainda, de Portugal, Chile e Peru. O evento aconteceu de maneira online pelo canal do YouTube - Critinfância - e envolveu a participação de 2400 pessoas de diversos estados brasileiros e, ainda de Portugal, Chile, Peru, Argentina, Inglaterra. O grupo de participantes contou com profissionais de diversas áreas do conhecimento: pedagogia, psicologia, filosofia, e outras e, ainda, professores da educação básica, do ensino superior, de educação especial, acadêmicos da graduação, pós-graduação de diversas áreas.

Sobre isso, evidencia-se que a docência com crianças, nesse sentido, não se limita a formação inicial, mas sobretudo pela formação contínua em prol de um arcabouço substancial de fundamentos teóricos e práticos do ensino. Diante disso, há a necessidade de desenvolver um movimento dialético e reflexivo em relação ao processo de educar a criança por meio da interlocução entre a Infância e a Teoria Crítica. Ainda, acolher e minimizar, por meio da formação docente, as desigualdades sociais e educacionais em defesa de uma educação da infância atenta às condições de cada comunidade educativa e, que garanta os processos democráticos de aprendizagem e desenvolvimento integral da criança. Para tanto, a qualidade do ensino depende da formação docente imbuída da interação entre o indivíduo e o contexto social a que pertence. Em relação ao tempo vivido pela pandemia mundial do Coronavírus, os espaços formativos voltados à criança precisam estar atentos ao direito de oferecer uma educação mais democrática e humanizadora.

Por meio da crítica imanente tem-se o desafio de expor a tensão dialética entre o horizonte de sentidos do pensamento e da educação e, a tentativa de domínio da realidade existente pelas trilhas da formação crítica e humanizadora de professores em sintonia com as especificidades da infância.

\section{CRITINFÂNCIA: UMA PROPOSTA FORMATIVA PARA PROFESSORES DA INFÂNCIA}

Nos profusos desafios que se impõem neste contexto contemporâneo, urge anunciar a necessidade de (re) pensar a formação de professores e o sentido de educar a criança em tempos obscuros. As ameaças deste tempo social pandêmico podem ser materializadas por esta nova configuração da educação da infância que se vê marcada pela prestação de serviço e, porque não, 
pelo retrocesso. Essa compreensão, além de não adequada aos processos educativos, vem impactando as dinâmicas familiares e afetando sobremaneira o trabalho docente que, neste contexto incerto precisam ser revisitados na relação entre professores-crianças e crianças-crianças; bem como escola-família e família-escola.

Se o mal-estar docente já se revelava em tempos anteriores, pois isso não é algo novo. Com a pandemia, a situação do professor e seu quadro de desprestigio social se tornou mais enfático, principalmente, quando autoridades macrossociais lhe depositaram instruções e ações emergências em tempos de dor e sofrimento no mundo. Os sintomas de enfraquecimento da formação se fazem observar por toda parte, até mesmo no território das pessoas aparentemente providas de certa intelectualidade. Silva (2019, p.60) ratifica que "no limite da racionalidade reduzida à mera instrumentalidade, a liberdade tão almejada pelos sujeitos só passa a ser possível se o pensamento for autorreflexivo, ou seja, aprender a 'pensar sobre si mesmo"'. Ainda, a "ferida" que estava aberta denominada desigualdade, com o novo tempo social, se torna agravada.

Diante as múltiplas formas de obediência refletidas pelas propostas virtuais e tecnológicas do processo de educar, há o despreparo da escola da infância, que diante do caos, promove barbárie com repetidas atividades em número quantitativo evidente, desconsiderando os direitos da criança e a própria condição de sua humanidade. Professores e gestores "saltam", sem perceber, da plateia para o palco em uma visão teatral de obediência e, ao mesmo tempo silenciada mediante a sustentação da farsa catastrófica de uma democracia acrítica que tenta levantar a bandeira da humanização da vida. Consequentemente, há a banalização do conhecimento pelo conteúdo quantitativamente depositado nas crianças como forma de garantia do ano letivo, bem como o cumprimento de carga horária e do "repasse" das atividades pedagógicas consideradas como essenciais para o processo formativo via tecnologia. Entretanto, essas experiências vividas neste contexto precisam ser contadas não somente pelos que veem, mas principalmente, pelos que vivem esta realidade metálica.

Nesse contexto a educação infantil e a formação docente se veem cercadas, por um lado, pela lógica da produção capitalista, e por outro lado, pela suposta crise dos fundamentos referenciais no que tange a compreensão sobre a infância e a criança e seu desenvolvimento em tempo de crise. A dispersão dos rumos dessa crise revela as fragilidades na (re) formulação de concepções educativas, com certa ilusão de que as reformas didático-pedagógicas de ensino contribuem, substancialmente, para o sentido de educar a infância nesse tempo de incertezas.

Diante disso, o projeto de pesquisa e extensão intitulado "Critinfância: novas trilhas e sentidos para a educação da infância em tempos de resistência" a partir do Grupo de Estudos e Pesquisa em Educação, Infância e Teoria Crítica (GEPEITC/CNPq) da Universidade Estadual de 
Londrina objetivou refletir sobre o processo formativo docente na educação da infância em tempos de resistência, bem como contribuir para o processo de (re) invenção do trabalho docente à luz da formação e humanização da criança. De modo particular, objetivou analisar o processo formativo docente e o sentido de educar a infância em tempos de pandemia e pós-pandemia; refletir sobre os saberes e fazeres de professores e sua relação com as crianças e, estas com outros pares e, promover a formação inicial e continuada de professores a partir de produções científicas e disseminações em formato de artigos em periódicos, organização de dossiê, organização de coletâneas e de simpósios e congresso nacionais e internacionais.

A partir disso, foi desenvolvido um trabalho de materialização da proposta por meio da criação de diversos canais de comunicação virtual e midiática, a fim de que pudesse acolher os professores em contextos atuais, tais como: Sites, Instagram, YouTube. A partir desses canais de comunicação, preocupou-se em contribuir e acolher os professores da infância mediante o caos instalado via ensino remoto e aulas online.

Por meio da necessidade de desenvolver um movimento reflexivo em defesa de uma educação da infância atenta às condições de cada comunidade educativa e, que garanta os processos democráticos de ensino e aprendizagem; ampliou-se, também, a possibilidade de diálogo com outros contextos sociais e culturais. Assim, surgiu a intencionalidade revelada por meio do IV Simpósio Nacional e I Simpósio Internacional de Infância, Educação e Teoria Critica, a partir da temática central derivada do Projeto de pesquisa e extensão já nominado.

E, ainda, pela possibilidade de tecer outros diálogos e parcerias com profissionais que atuam no campo da educação, infância, formação e teoria crítica como foi possível desenvolver um trabalho para além do território demarcado (Brasil) e, desse modo, pode-se pensar em um evento com a participação de outros países, como é o caso de Portugal, Peru, Argentina.

Assim sendo, por meio da interlocução e diálogo entre as Universidades tendo como foco o sentido de educar a criança em tempos de crise, é possível dar continuidade ao legado produzido historicamente pelos processos educativos da infância comprometidos com a vida da criança e com o seu desenvolvimento integral, em seus aspectos físico, psicológico, intelectual e social. Para tanto, esta proposta, se firmou na ação de acolher os professores pelo processo da formação e reflexão da práxis. Este processo formativo revelado pela organização do evento foi possível à luz da autorreflexão crítica tão ressaltada por Adorno (1995) enquanto processo dialético de apropriação subjetiva e formativa da cultura.

A qualidade do ensino depende da formação docente envolvida pela interação entre o sujeito e o contexto social a que pertence. Nesse sentido, enquanto professores em formação e, também, formadores de professores é preciso estar imbuídos dos fundamentos críticos e 
humanistas do conhecimento e de "uma construção inter e intra pessoal, não sendo, por isso, um processo solitário" (SARMENTO, 2016, p.78). Desse modo, há a possibilidade de articular a formação inicial e continuada de professores e, na travessia, potencializar a mudança e ou (re) invenção.

A partir das problemáticas apresentadas no Projeto de Pesquisa e Extensão, tais como: Em tempos de travessia, como tem se constituído o processo formativo e de (re) invenção do trabalho docente na educação da infância? Outras questões de cunho secundário para um (re) pensar docente: a) Qual o sentido de educar a criança com vistas ao processo de acolhimento e minimização ante as desigualdades sociais e educacionais? b) Que legado produziremos aos processos educativos das crianças pequenas, principalmente no que tange a formação da vida integralmente e de sua humanidade? c) Como humanizar a educação da infância em tempos de Covid-19 sem cair na retórica da memória metálica? d) Como auxiliar no processo formativo docente em favor da necessária retomada pós pandemia? Esses questionamentos potencializamnos no processo de organização teórico-metodológica desta proposta.

Pelas trilhas da (re) invenção da infância e educação infantil foi possível estabelecer visibilidade à produção e à difusão formativa docente sobre a criança enquanto ser humano de direito à uma educação que garanta a vida e a experiência de aprender e brincar dignamente pelos limiares do pensar crítico, criativo e expressivo.

Desse modo, o evento foi organizado entre os dias 06 e 09 de outubro de 2020 por meio de atividades diversas, tais como: Conferências, Palestras, Relatos de Experiência, Roda de Conversa, Apresentação do Projeto Critinfância, Comunicação de Projetos de Pesquisa de orientandos de mestrado e doutorado e que estão em desenvolvimento da pesquisa e, vinculados aos Grupos GEPEITC e GEFOCS. Contou com um arranjo temporal a partir de

A conferência de Abertura, no dia 06 de outubro, abarcou a discussão acerca da infância, formação de professores e interação na educação das crianças a partir da Temática "O que fazemos com o que fazem conosco: trilhar caminhos em interação" proferida pela professora e doutora Maria Tereza Jacinto Sarmento da Universidade do Minho (UM), Braga, Portugal. A segunda palestra trouxe a discussão sobre "Olhares Plurais da Educação da Infância: valores estéticos, éticos e políticos" ministrado pela professora doutora Luzia Batista de Oliveira Silva da Universidade de São Francisco (USF). A reflexão humanizadora sobre os olhares plurais da educação da infância envolveu os participantes que puderam desenvolver o processo de autorreflexão, principalmente no que tange às crianças esquecidas e sem voz do Brasil e demais países. A partir da temática " $A$ educação da Infância em tempos de pandemia: dialogando com outras bases teóricas" pode-se pensar a infância e a educação em tempos de pandemia a partir de outras bases teóricas que não somente as que 
versam pelos limiares da Teoria Crítica. Nesta discussão, à luz dos pressupostos da Teoria Histórico-Cultural, as professoras doutoras Heloísa Irie Saito da Universidade Estadual de Maringá (UEM) e Marta Silene Ferreira Barros da Universidade Estadual de Londrina (UEL) discorreram sobre a educação da infância nesse contexto e os olhares emancipatórios em defesa do desenvolvimento humano e das máximas qualidades.

Ainda, o evento trouxe a discussão sobre "Educación y Pandemia em América Latina: La experiencia en el Perü' proferida pelo professor doutor Eduardo José Campechano-Escalona da Universidade César Vallejo, Peru. A partir dos fundamentos e dados da educação do Peru, pudemos desenvolver confluências com a realidade brasileira que tem se acometido das mesmas dificuldades. A professora Lucia Merlos de Buenos Aires, Argentina pode suavizar de maneira lúdica o evento com a apresentação temática sobre "La danza em la educación de primaria de la Provincia de Buenos Aires" desenvolvendo uma discussão atual e pertinente sobre a educação da infância e o desenvolvimento do corpo e movimento por meio da dança. Ainda, pelos mesmos sentidos de educar voltados ao desenvolvimento do corpo, principalmente em um contexto em que o sedentarismo tem invadido a vida de nossas crianças, a professora mestre Graciela Tabak fez uma belíssima explanação sobre "El lugar del cueppo en los professorados del maternal", com vistas a uma ação docente envolvida pela defesa de uma educação da criança com mais possibilidades corporais de aprendizagem, principalmente no que tange ao ensino remoto que tem colocado as crianças em situações de fragilidades e implicando no seu desenvolvimento pelo extensivo tempo frente às telas.

Sem perder o contexto vigente a discussão também envolveu a temática sobre "Criança e Brinquedos: uma relação inquestionável? a partir dos conhecimentos da professora doutora Aliandra Mesomo Lira da Universidade Estadual do Centro-Oeste (UNICENTRO) de Guarapuava, Paraná. À luz dos pressupostos foucaultianos discutiu sobre os supostos perigos em relação ao brinquedo enquanto objeto de governamento da infância e de uma ludicidade disciplinada pelo consumo.

Com a roda de conversa houve a oportunidade de trazer professores da educação infantil de diversos municípios e que desenvolvem um trabalho pedagógico na qualidade de professores e gestores da infância. Nesse sentido, por meio das "Vivências e Experiências de professores e gestores da infância" pode-se vislumbrar o que tem sido desenvolvido antes e durante a pandêmica, bem como dirigir possíveis focos de esperança para um trabalho mais humanizador do ensino. A discussão sobre o projeto de pesquisa e toda a intencionalidade do evento não foi desconsiderada, uma vez que por meio da apresentação da coordenadora professora Doutora Marta Regina Furlan de Oliveira da Universidade Estadual de Londrina (UEL) sobre o tema 
"Critinfância: novas trilhas e sentidos para a educação infantil em tempos de resistência" pode revelar as intencionalidades da proposta de modo que a educação da infância se volta para o compromisso com a formação da criança e da sua humanidade.

A discussão do evento de modo geral potencializou a discussão sobre a tensão existente entre educação e formação cultural no cenário da razão instrumental refletindo, afinal, para onde a educação deve conduzir, principalmente, quando nos deparamos com as coordenadas da nova conjuntura econômica, política, histórica, cultural e social que, com suas luzes e suas sombras, já se tornam visíveis por toda parte, propagando a instrumentalidade do saber e da razão.

As ações, nesse sentido, devem ser correlacionadas com a formação de professores munida da crítica imanente acerca do trabalho pedagógico e educativo com as crianças pequenas. A educação da infância, nesse sentido, precisa ser pensada e ressignificada pelo processo formativo intencional e pedagógico, do que simplesmente intermediar modelos e ideais preestabelecidos. Assim, a educação em Adorno (1995, p.141) imprime a "produção de uma consciência verdadeira" e reificada pela autorreflexão crítica e, ao mesmo tempo, aponta para uma dimensão formativa (inicial e continuada) a ser desenvolvida enquanto movimento de resistência ao instituído nesta travessia.

A necessidade de uma educação da infância crítica expõe a necessidade de decifrar as condições e os determinantes históricos que causam o modo ao qual os indivíduos estão submetidos. Adorno aponta para uma "educação para a contradição e resistência". A educação tem a empreitada de "fortalecer a resistência do que fortalecer a adaptação" (ADORNO, 1995, p.144); sobretudo, para se contrapor às formas de degeneração educativa, que promove o conformismo e a submissão servil do conhecimento. Em Adorno educar significa levar a sério o tempo necessário para a construção de sentido que se dá na relação pedagógica, principalmente pelo indescritível empobrecimento do pensar, da linguagem e expressão humana.

Por conseguinte, Sarmento (2016, p.78) ratifica que é necessário refletir sobre a identidade dos educadores da infância pelo processo de análise da construção social a partir de sua própria história e ou experiência com a história do grupo e contexto onde se desenvolver a ação educativa e pedagógica, "transformando e permitindo-se transformar, nessa teia de interações numa forma própria de ser e de agir”.

\section{CONCLUSÃO: EM BUSCA DE TRILHAS E NOVOS SENTIDOS PARA A EDUCAÇÃO DA INFÂNCIA}

Ao retomar o objetivo central deste texto, retomamos o significado do trabalho formativo docente em relação ao sentido de educar em tempos de resistência. Há, nesse sentido, a 
necessidade de direcionarmos para o olhar de (re) invenção e busca de novos sentidos ao processo formativo docente com vistas a desbarbarização do trabalho na educação da infância por meio da resistência e crítica imanente em tempos espúrios.

No Brasil e porque não, no Mundo, verifica-se que essa estratégia está vinculada ao tempo vivido atualmente, em contexto pandêmico, principalmente no campo formativo de professores que atuam na educação da infância. O que desentoa nesta ironia do destino formativo é o empacotamento de um discurso uniforme acerca do sentido de educar a infância e uma suposta complexidade de ações que nada mais são do que a continuação do mesmo (ADORNO, 1995). Há demasiadamente uma crise de valores expressos, sobretudo pelas agressões éticas e de violências do saber que, de certa forma, se materializam na ausência dos fundamentos teórico-metodológicos em detrimento das especificidades do trabalho pedagógico docente na infância com crianças de 0 a 5 anos.

Em contraposição a esses argumentos, Sarmento (2016) cita Lilian Katz (1985) que é uma pesquisadora americana e investigadora dos assuntos e problemáticas relacionadas a educação da infância. Com base em Katz (1985), Sarmento (2016, p.79) afirma sobre as especificidades docentes na educação da infância, por meio de quatro elementos fundamentais:

1. A essencialidade do trabalho realizado com crianças até aos $5 / 6$ anos para que a sociedade se desenvolva da melhor maneira; 2 . O valor altruísta da profissão, defendendo a importância do voluntarismo entendido como o sentido de missão ${ }^{3}$ e que ultrapasse o mero sentido técnico; 3. A autonomia profissional baseada em conhecimentos especializados, em princípios e técnicas; e, por fim, 4. A relevância das associações profissionais para a construção dos códigos éticos. (grifo nosso).

A partir das considerações elencadas por Sarmento (2016) e, ao tecer confluências com outros autores que tratam sobre este objeto de estudo, é necessário retomar o olhar em relação a infância e a criança neste contexto de travessia (Século XXI). Por conseguinte, ao buscar as contribuições benjaminianas, vê-se uma infância que considera a criança como sujeito envolvido pela complexidade da trama social, imersa na problemática histórica de seu tempo. Em Benjamin (1985), é possível ver o tempo da infância a partir do que ela tem e não do que lhe falta: "como presença, e não como ausência; como afirmação e não como negação, como força, e não como incapacidade" (KOHAN, 2007, p. 101). Essa mudança de percepção promove a inter-relação dos

\footnotetext{
3 Esse termo, no contexto da discussão de Sarmento (2016) está associado ao processo de formação, intencionalidades pedagógicos, compromisso profissional, ético e afetivo-social, domínio do conhecimento e das especificidades do trabalho com a criança de 0 a $5 / 6$ anos.
} 
temas "tempo, infância e experiência" em sintonia com nascimentos, novos inícios para o pensamento, para o pensado e para o não-pensado nesta terra comum.

Em consonância com Benjamin (1985) e Kohan (2007), Agamben (2014, p.10), em sua obra "Infância e história: destruição da experiência e origem da história", evoca que a "in-fância" “não é simplesmente um fato do qual seria possível isolar um lugar cronológico, nem algo como uma idade ou um estado psicossomático que uma psicologia ou uma paleoantropologia poderiam jamais construir como um fato humano independente da linguagem”. Acrescenta que se a condição do pensamento humano é constituída pelo seu modo de articular o problema nos limites da linguagem, desse modo, o conceito de infância é, então, uma tentativa de pensar estes limites em uma direção que não é aquela, trivial, do inefável; mas sobretudo, a singularidade que a linguagem deve significar enquanto presença no mundo e com o mundo.

Em se tratando da educação da infância brasileira, o que não é diferente em alguns outros países, há a urgente necessidade de analisar criticamente as questões candentes na educação infantil, porque as crianças ainda são crianças. Considerando o trabalho desenvolvido ao longo dos anos na formação de professores, é preciso fomentar o desejo e a luta por um trabalho humanizador da infância no sentido de garantir o acolhimento pelo ensino e educação de mais qualidade revelada na necessidade de se pensar em um lugar em que seja garantido o direito da criança ser criança e de viver um tempo de infância envolvido por experiências e descobertas.

A partir desse entendimento acerca do processo da educação infantil far-se-á necessário refletir sobre a organização do cotidiano educativo com as crianças em tempo de travessia, no sentido de compreender esse processo de aprendizagem e desenvolvimento humano à luz de uma proposta educativa regida pelas concepções claras sobre educação infantil, rotina, tempo e interações, no sentido de que o professor possa efetivamente desenvolver um trabalho que priorize a emancipação da criança por meio da curiosa descoberta da aprendizagem, abrindo possibilidades para que tanto a criança quanto ele possam experienciar a aventura fascinante pelo conhecimento e, quem sabe, possam até se molhar, "[...] transformando-se em um lugar desconfortável, úmido, mas cheio de aventura, verdadeiro intenso, fascinante" (RABBITTI, 1999, p.10).

Nesse prisma, entende-se e defende-se a educação infantil enquanto lugar desafiador e promotor de descobertas por meio de ações efetivas da criança com seus pares em prol da ampliação do processo de aprendizagem e desenvolvimento infantil. Nesse movimento, as crianças precisam expressar livremente seus medos, inseguranças, leituras de mundo, impressões, hipóteses, além de que precisam ter espaços para conhecer, perguntar, elaborar hipóteses, 
estabelecer relações e aprender de maneira real e significativa. Do parque de areia, com seus balanços construídos nas grandes árvores enquanto cenário lúdico para as crianças, às salas de referência, todas as organizações expressam como vemos, percebemos e pensamos ser a criança e sua aprendizagem.

Entretanto, muitos (as) professores (as) veem a infância apenas como um período de carências (afetivas, físicas, sociais), dado que as maneiras próprias da criança agir e interagir nem sempre são levadas a sério. Submetidas desde cedo às imposições dos adultos ou paparicadas e/ou deixadas à deriva em seu desenvolvimento, as crianças pequenas são privados de um ambiente organizado e intencionalmente planejado. Diante disso, o cotidiano na educação infantil, também conhecido por rotinas pedagógicas, muitas vezes, é organizado por um conjunto de ações culturalmente tradicionais que evidencia os hábitos consolidados devido à inércia institucional e hábitos indiscutíveis, frutos da tradição e de um saber consolidado na prática que, de certa forma, impedem a compreensão, pelos profissionais envolvidos, dos elementos constitutivos desse cotidiano.

$\mathrm{Na}$ busca por uma melhor compreensão, é importante considerar que esse cotidiano de educação, aprendizagem e desenvolvimento de crianças está envolvido por elementos constitutivos de uma rotina de trabalho e de aprendizado e, que podem ser explicitados por: "[...] organização do ambiente, o uso do tempo, a seleção e as propostas de atividades, a seleção e a oferta de materiais" (BARBOSA, 2006, p.117). Sobre esse território educativo da infância, Sarmento (2016) revela a necessidade de pensar em três elementos sinalizadores no que tange ao processo educativo de professores, tais como: a) o trabalho docente desenvolve-se prioritariamente com as crianças pequenas; b) a relação entre professores e crianças se constitui um dos marcos decisivos no processo de aprendizagem infantil; c) a responsabilidade profissional dos educadores da infância devem estar sincronizadas com o compromisso ético da docência; d) a relação educativa de professores e crianças está marcada por imagens de infância e de crianças.

Para além dessa prática de silenciamento da infância está a grande empreitada lúdica no sentido de que o professor possa reservar o tempo para explorar juntamente com as crianças, as necessidades explicitadas pelo brincar, seja pelo brincar dirigido ou protagonizado (livre). Moyles (2002, p. 33) afirma que "[...] o brincar dirigido refere-se principalmente ao processo. A segunda situação de brincar inclui processo e modo, e é dentro desse tipo de brincar que os professores devem procurar a aprendizagem real".

Por meio do brincar livre, exploratório, as crianças aprendem alguma coisa sobre situações, pessoas, atitudes e respostas, materiais, propriedades, texturas, estruturas, atributos visuais, auditivos e 
cinestésicos. Por meio do brincar dirigido, elas têm uma outra dimensão e uma nova variedade de possibilidades estendendo-se a um relativo domínio dentro daquela área ou atividade. Por meio do brincar livre subsequente e ampliado, as crianças provavelmente serão capazes de aumentar, enriquecer e manifestar sua aprendizagem (MOYLES, 2002, p. $33)$.

Desse modo, o brincar deve fazer parte da rotina pedagógica como uma possibilidade de ampliação do universo do conhecimento infantil, uma vez que envolvidas por uma rotina lúdica e alegre, colorida e desafiadora, as crianças se constituem como sujeitos humanizados, com uma certa organização da vida social e individual que se articula com o funcionamento psicológico próprio, ou seja sua subjetividade que, no processo de desenvolvimento, vai sendo ampliada pelas necessidades e desejos enquanto sujeito social.

Assim, pelas trilhas da desbarbarização é possível pensar em uma formação comprometida com a vida e com o direito à criança a uma educação digna e de qualidade. Entretanto, não se deve abrir mão de uma educação para todos, deve-se pensar em caminhos que não afete a democratização desse direito. Para isso, afirma-se: Não são apenas números, são pessoas. Não são dados, são vidas. Nãos são apenas vidas, são vidas que importam. Nesse prisma, é preciso resistir a todo tipo de banalização da morte e à desumanização da doença (travessia) que transborda para a educação das crianças pequenas. A questão é simples: A educação da infância não está para prestar serviços, mas sim para garantir direitos. Educação é direito e, defender isso é o dever de todos, principalmente dos profissionais envolvidos com as crianças de 0 a 5/6 anos, visto que a educação em sentido pleno é a educação para todos e sua integralidade é para uma formação humana. Qualquer "jeitinho" educacional pode significar um ato fatal para a educação pública, igualitária e de direitos. Assim, uma educação antifascista não abre mão da democracia, da autonomia e do direito pelas crianças de um lugar onde possa acontecer a vida, as relações estabelecidas entre adultos e crianças e entre as crianças e, finalmente, um lugar que as crianças possam fazer experiências.

\section{REFERÊNCIAS}

ADORNO, T. Educação e emancipação. Trad. Wolfgang Leo Maar. São Paulo: Paz e Terra, 1995.

AGAMBEN, G. O que é um dispositivo? e o amigo. Tradução: Vinícius Nicastro Honesko. Chapecó: Editora Argos, 2014. 
BARBOSA, Maria C. S. A Rotina nas Pedagogias da Educação Infantil: dos binarismos à complexidade, Currículo sem Fronteiras, v.6, n.1, p. 56-69, Jan/Jun2006. Disponível em: http://www.curriculosemfronteiras.org/vol6iss1articles/barbosa.pdf. Acesso em 01/03/2021.

BENJAMIN, W. Obras escolhidas II: rua de mão única. 5. ed. São Paulo: Brasiliense, 1985.

KOHAN, W. O. Infância: entre educação e filosofia. Belo Horizonte: Autêntica, 2007.

MOYLES, J. R. Só brincar? O papel do brincar na educação infantil: tradução de Maria Adriana Veríssimo Veronese. Porto Alegre: Artmed, 2002.

SARMENTO, T. Infâncias e Crianças em Narrativas de Educadoras de infância. In: PASSEGGI, FURLANETTO e PALMA (org). Pesquisa (auto) biográfica, infâncias, escola e diálogos intergeracionais. Curitiva: Editora CRV, 2016. (p. 77-94).

SILVA, L. B. O (orgs). Educação, estética e experiência: entre saberes e práticas na contemporaneidade. São Paulo: Editora Livraria da Física, 2019. (p.15-29). 